Original Research Paper

\title{
Evaluation of Different Drugs in Down-Regulation of Efflux Pump Genes expression in Methicillin-Resistant Staphylococcus aureus Strains
}

\author{
Manu Chaudhary, Santosh Kumar Patnaik and Anurag Payasi \\ Venus Medicine Research Centre, Hill Top Industrial Estate, Bhatoli Kalan, Baddi, H.P.-173205, India
}

\author{
Article history \\ Received: 25-07-2014 \\ Revised: 22-08-2014 \\ Accepted: 05-01-2015 \\ Corresponding Author: \\ Anurag Payasi \\ Venus Medicine Research \\ Centre, Hill Top Industrial Estate, \\ Bhatoli Kalan, \\ Baddi, H.P.-173205, India \\ Email: ccmb@vmrcindia.com
}

\begin{abstract}
Antimicrobial resistance caused by efflux systems is not widely studied in Staphylococcus aureus. In the present study, prevalence of NorA and NorB efflux pumps was studied in thirteen Methicillin-Resistant Staphylococcus aureus (MRSA) strains using a pair of primers with Polymerase Chain Reaction (PCR). Antibiotic susceptibility study in NorA and NorB efflux positive isolates was carried out according to the Clinical and Laboratory Standards Institute guidelines. To evaluate the effects of various drugs at half of their MIC on NorA and NorB efflux pump, expression of NorA and NorB genes was measured through semi-quantitative PCR. Our results demonstrated that out of 13 MRSA strains, 8 strains were both NorA and NorB positive and 2 strains were NorA positive. Susceptibility data revealed that Vancoplus appeared to be the most active antibacterial against NorA and NorB efflux pumps positive MRSA strains with MIC values 0.25 to $0.5 \mu \mathrm{g} \mathrm{mL}$. The second most active antibacterial agent was teicoplanin with MIC values 0.5 to 1 $\mu \mathrm{g} \mathrm{mL} L^{-1}$. The MICs of vancomycin and daptomycin ranged from 32 to $64 \mu \mathrm{g}$ $\mathrm{mL}^{-1}$. Treatment of MRSA strains possessing NorA and NorB efflux pumps with Vancoplus caused significant down-regulation of the expression of NorA and NorB genes $(\mathrm{P}<0.001)$ as compared to the control (without treatment) whereas other drugs such as vancomycin, linezolid, teicoplanin and daptomycin failed to produce any significant changes in the expression of these genes $(\mathrm{P}>0.05)$. From the above results, it can be concluded that Vancoplus (vancomycin+ceftriaxone+VRP1020) can be one of the best options to treat infections caused by MRSA possessing NorA and NorB efflux pumps.
\end{abstract}

Keywords: Clinical Isolate, Methicillin-Resistant Staphylococcus aureus, Vancoplus

\section{Introduction}

Resistance of microorganisms to antibiotics which is associated with several mechanisms such as enzymatic inactivation of the drugs (Sabatini et al., 2012), alteration of the drug target (s) (Ruiz et al., 2003), reduction of intracellular drug concentrations by changes in membrane permeability (Nikaido, 2003) and over expression of efflux pumps (Nikaido, 2003; Li, 2009) has become a great problem across the world. Nowadays, of these mechanisms, recently efflux pumps have been recognized as a major factor for resistance in both Gramnegative and Gram-positive bacteria (Jadwiga et al., 2013; Saiful et al., 2008). These are transporter proteins involved in the extrusion of toxic substrates including all classes of antibiotics from within cells to the external environment. Till date, four families of efflux pumps namely, MFS (major facilitator super family), Small Multidrug Resistance (SMR), ABC (ATP-binding cassette) and MATE (multidrug and toxic compound extrusion) have been reported in Gram-positive bacteria (Jarmula et al., 2011; Kaatz et al., 2005). Among these efflux pumps, MFS types of efflux pumps are predominantly present in Gram-positive bacteria such as NorA, NorB, MdeA, Tet38 (Staphylococcus aureus), LmrB, Bmr, Bmr3, Blt (Bacillus subtilis), MefA (Streptococcus pyogenes), MefE (Streptococcus pneumoniae) or CmlR (Streptococcus coelicor) (Jarmula et al., 2011; Borges-Walmsley et al., 2003; Poole, 2005; Markham and Neyfakh, 2001; Sabatini et al., 2012). 
Methicillin-Resistant S. aureus (MRSA) is a major multidrug resistant Gram-positive bacterium that causes various types of Healthcare-Associated Infections (HAIs) resulting in a high death rate (Kallen et al., 2010).

Several studies have shown that increased resistance to antibiotics, biocides and dyes has been associated with NorA and NorB mediated efflux pumps (Handzlik et al., 2013; Sabatini et al., 2012; Truong-Bolduc et al., 2005; 2011; 2012; Ding et al., 2008). However, antimicrobial resistance associated with NorA and NorB efflux pumps is poorly characterized in $S$. aureus (Handzlik et al., 2013). NorA uses proton motive force to energize the transport of antimicrobial compounds across the cell membrane (Neyfakh et al., 1993). On the other hand, NorB efflux pump is structurally similar to the efflux pumps, Blt (41\%) and Bmr (30\%) of B. subtilis, as well as to the NorA $(30 \%)$ and QacA (39\%) of $S$. aureus. The wide specificities of multidrug efflux systems suggested their overexpression might result in the efflux of intracellular concentrations of many such agents, causing an impact on their clinical efficacy (Handzlik et al., 2013; Truong-Bolduc et al., 2011).

Efflux Pumps Inhibitors (EPIs), which are compounds targeting the efflux activity and/or pump components, have been identified as promising therapeutic agents, as they may restore the activity of standard antibiotics (Truong-Bolduc et al., 2011). The combination of antibiotics and efflux pump inhibitors such as Ethylene Diaminetetraacetic Acid (EDTA) is expected to increase the intracellular concentration of antibiotics, decrease the intrinsic bacterial resistance to antibiotics, reverse the acquired resistance associated with efflux pumps overexpression and reduce the frequency of the emergence of resistant mutant strains (Chaudhary et al., 2012). In the present investigation, prevalence of NorA and NorB efflux pumps among MRSA strains was evaluated and further effects of different drugs on NorA and NorB gene expression were studied.

\section{Materials and Methods}

\section{Drugs}

The following antibiotics were used in this study: A combination of ceftriaxone sodium and vancomycin hydrocloride with VRP1020 (Vancoplus; Venus Remedies Limited, Chandigarh, India), vancomycin (Vancocin-CP, Astra Zeneca Pharma India Limited, Banglore, India) teicoplanin (Ticocin, Cipla Limited, Mumbai, India), linezolid (Walibur, Novartis India, Limited, Mumbai, India) and daptomycin (Cubicin; Novartis Pharmaceuticals, United Kingdom).

\section{Collection of S. aureus Strains}

A total of 27 Staphylococcus aureus strains were obtained from Sanjay Gandhi Post Graduate Institute of Medical Sciences (SGPGIMS), Raebareli Road, Lucknow, India. Hundred microliter of glycerol stock culture of each of $27 \mathrm{~S}$. aureus strains was transferred to $100 \mathrm{~mL}$ of autoclaved Soybean Casein Digest Medium (Hi-Media, Mumbai, India) and grown for $14-16 \mathrm{~h}$ at $37^{\circ} \mathrm{C}$.

\section{Growth of S. aureus Strains and their Identification}

Mannitol salt agar (Hi-Media, Mumbai, India) was used as a selective medium for $S$. aureus. All the strains were reinoculated onto mannitol salt agar plates and then incubated at $37^{\circ} \mathrm{C}$ for $24-48 \mathrm{~h}$. Mannitol fermenting yellow colored colonies were selected, subcultured and subjected to reidentification based on morphological and biochemical studies (Akbar et al., 2013).

\section{Screening for MRSA}

A 0.5 McFarland standard suspension of each $S$. aureus strain was prepared in Mueller-Hinton Broth (MHB, Hi-Media, Mumbai, India) and plated on Mueller-Hinton Agar (MHA, Hi-Media, Mumbai, India) plates containing $2 \% \mathrm{NaCl}$. An oxacillin $(1 \mu \mathrm{g})$ disk was placed on the surface of the plates and incubated at $35^{\circ} \mathrm{C}$ for $24 \mathrm{~h}$. Zone diameter of $<10 \mathrm{~mm}$ is considered as resistant, $>13 \mathrm{~mm}$ as susceptible whereas $11-12 \mathrm{~mm}$ is considered as intermediate.

\section{DNA Isolation}

DNA from all MRSA strains was isolated as following: five milliliter of each overnight grown MRSA strain was centrifuged at $5000 \mathrm{rpm}$ for 4 minutes at $25^{\circ} \mathrm{C}$ and pellets were washed once in phosphate buffer saline (PBS; $0.05 \mathrm{M}$; pH 7.2). After addition of $0.2 \mathrm{ml}$ ice-cold solution 1 (25 mM Tris-HCl pH 8.0; 10 mM EDTA pH 8.0 and $50 \mathrm{mM}$ glucose) and $0.4 \mathrm{ml}$ of solution $2(1 \%$ $\mathrm{SDS} ; 0.2 \mathrm{~N} \mathrm{NaOH}$ ), Eppendorf tubes were inverted five times gently and allowed to stand at room temperature for 5 minutes. Subsequently, $0.3 \mathrm{~mL}$ ice-cold solution 3 ( $3 \mathrm{M}$ potassium acetate and $5 \mathrm{M}$ glacial acetic acid) was incorporated into each tube, inverted five times gently and allowed to stand on ice for 10 minutes. After centrifugation $(14000 \mathrm{rpm}, 2 \mathrm{~min})$, pellets were resuspended in $0.5 \mathrm{ml}$ of TE (Tris-EDTA, $0.05 \mathrm{M}, \mathrm{pH}$ 8.0) and incubated for $5 \mathrm{~min}$ at $65^{\circ} \mathrm{C}$. Following incubation, $0.5 \mathrm{ml}$ of phenol-chloroform-isoamyl alcohol $(25: 24: 1)$ was added to each tube and centrifuged at $14000 \mathrm{rpm}$ for $3 \mathrm{~min}$ at $4{ }^{\circ} \mathrm{C}$. The supernatant $(\leq 800 \mu \mathrm{L})$ containing the DNA was transferred to a clean $2.0 \mathrm{ml}$ tube containing $800 \mu \mathrm{L}$ of ice-cold ethanol $(70 \% \mathrm{v} / \mathrm{v})$. The DNA solution was mixed with the ethanol by inverting the tubes at least 15 times and centrifuged at $14000 \mathrm{rpm}$ for $2 \mathrm{~min}$. The pellet was air dried for $5 \mathrm{~min}$ and re-dissolved in $100 \mu \mathrm{L}$ of Tris-EDTA buffer. The 
electrophoresis was run in $1.0 \%$ agarose gel. After electrophoresis at 70 volt for 55 minutes the gel was photographed for analysis of integrity of extracted DNA.

\section{Minimum Inhibitory Concentration (MIC)}

MIC of each drug was determined by the agar dilution method according to the (CLSI, 2013) guidelines. MIC was defined as the lowest concentration of a drug that inhibits the visible growth of a microorganism when incubated at $37^{\circ} \mathrm{C}$ for $18 \mathrm{~h}$

\section{Identification of NorA and NorB Genes in MRSA Strains}

All the MRSA strains were analyzed for presence of NorA and NorB genes using following primers with PCR. Primers were obtained from Sigma Aldrich Chemicals Private Limited, Banglore, India. The following primer sequences were used for NorA-F-5'TTCACCAAGCCATCAAAAAG-3'; NorA-R-5'CTTGCCTTTCTCCAGCAATA-3'; and NorB-F-5'AGCGCGTTGTCTATCTTTCC-3, 5',Nor-B-R-5' GCAGGTGGTCTTGCTGATAA-3'. for PCR amplifications, approximately $100 \mathrm{ng}$ of DNA was added to a $20 \mu \mathrm{L}$ mixture containing $0.5 \mathrm{mM}$ of dNTPs, 1.25 $\mu \mathrm{M}$ of each primer and $0.5 \mu \mathrm{L}$ of $3.0 \mathrm{U} \mu \mathrm{L}^{1}$ of Taq polymerase (Banglore Genei). Amplification was performed in an Eppendorf thermocycler (Germany) with cycling parameters, consisting of initial denaturation at $94^{\circ} \mathrm{C}$ for $5 \mathrm{~min}$ followed by 30 cycles $(30$ seconds of denaturation at $94^{\circ} \mathrm{C}, 30 \mathrm{~s}$ of annealing at $45^{\circ} \mathrm{C}$ for NorA and $53^{\circ} \mathrm{C}$ for NorB and $1 \mathrm{~min}$ of extension at $72^{\circ} \mathrm{C}$ ) and final extension at $72^{\circ} \mathrm{C}$ for $1 \mathrm{~min}$. The PCR products were analyzed on $1.0 \%$ agarose gel containing ethidium bromide. Staphylococcus aureus MTCC 737 was used as NorA-NorB negative strain.

\section{RNA Isolation}

Total RNA from untreated and treated MRSA strains with various drugs at their half of MIC was extracted using the method described elsewhere (Sung et al., 2003). Briefly, two milliliters of overnight grown MRSA strains were centrifuged at $5000 \mathrm{rpm}$ for $5 \mathrm{~min}$ at $4^{\circ} \mathrm{C}$ and pellet was washed with 1 X TE buffer ( $\mathrm{pH} \mathrm{8.0)}$, suspended in $1 \mathrm{ml}$ of TE buffer containing $0.2 \%$ Triton X-100. The suspension was incubated at $100^{\circ} \mathrm{C}$ for $10 \mathrm{~min}$ and thereafter immediately placed to an ice bath. After incubation, an equal volume of chloroform: Methanol (2:1) mixture was added, mixed thoroughly and centrifuged at $12000 \mathrm{rpm}$ at $4{ }^{\circ} \mathrm{C}$ for $10 \mathrm{~min}$. This step was repeated twice. Finally, RNA was precipitated by addition of 2 volumes of pre-chilled $100 \%$ ethanol to the supernatant and the mixture was kept at $-20^{\circ} \mathrm{C}$ for $4 \mathrm{~h}$ and then centrifuged at $12000 \mathrm{rpm}$ for $10 \mathrm{~min}$ at $4^{\circ} \mathrm{C}$. The pellet was air dried for $5 \mathrm{~min}$ and re-dissolved in 50 $\mu \mathrm{L}$ of DEPC water. The ratio of absorbance at $260 \mathrm{~nm}$ and $280 \mathrm{~nm}$ was used to assess the purity of RNA. A ratio of 2.0 is generally accepted as "pure" for RNA. RNA was stored at $-70^{\circ} \mathrm{C}$ until use.

\section{CDNA Synthesis}

Total RNA ( $2 \mu \mathrm{g})$ was converted to first strand CDNA as follows: Two microgram of RNA was added to $1 \mu \mathrm{L}^{-1}$ of oligodT primer and $9.2 \mu \mathrm{L}$ of water and the mixture was incubated at $65^{\circ} \mathrm{C}$ for $5 \mathrm{~min}$. After incubation, following reagents were added sequentially: $4.0 \mu \mathrm{L}$ of $5 \mathrm{X}$ RT buffer, $1.0 \mu \mathrm{L}$ of $0.1 \mathrm{M}$ DTT, $0.5 \mu \mathrm{L}$ of $10 \mathrm{mM}$ dNTPs and $0.3 \mu \mathrm{L}^{-1}$ of $20 \mathrm{U} \mu \mathrm{L}^{-1}$ Moloney Murine Leukemia Virus Reverse Transcriptase (MMLVRT), mixed well and the mixture was subsequently incubated at $37^{\circ} \mathrm{C}$ for $60 \mathrm{~min}$. The reaction was stopped by heating at $70^{\circ} \mathrm{C}$ for $10 \mathrm{~min}$. The resultant solution was CDNA which can be used for gene expression study by PCR.

\section{PCR Analysis}

PCR was performed using the CDNA as template. The primers for NorA and NorB genes were the same as mentioned above. 16S rDNA primers were used to amplify the $16 \mathrm{~S}$ rDNA as internal control and following sequences were used: 16S-F-5'AACTCTGTTATTAGGGAAGAACA-3' and 16S-R5'CCACCTTCCTCCGGTTTGTCACC-3'. For PCR amplifications, about $3 \mu \mathrm{L}$ of CDNA was added to a $20 \mu \mathrm{L}$ mixture containing $0.5 \mathrm{mM}$ of dNTPs, $1.25 \mu \mathrm{M}$ of each primer and 3.0 U of Taq polymerase (Banglore Genei) in 1x PCR buffer. Amplification was performed in an Eppendorf thermocycler (Germany) with the cycling parameters mentioned in section 2.7. PCR products were then electrophoresed on a $1.0 \%$ agarose gel containing ethidium bromide and intensity of each amplified band was analyzed using the image $\mathrm{J}$ software.

\section{Effect of Test and Comparator Drugs on NorA and NorB Gene Expression}

To evaluate the effects of drugs on expression of NorA and NorB genes, NorA and NorB positive MRSA strains were treated with all the selected drugs, vancoplus, vancomycin, linezolid, teicoplanin and daptomycin, at their half of MIC for $24 \mathrm{~h}$. Following treatment, total RNA was isolated as mentioned above. First strand CDNA was then synthesized from $2 \mu \mathrm{g}$ total RNA using reverse transcriptase (Invitrogen). The same strain without drug treatment served as a control. All experiments were carried out in triplicate and representative data are presented.

\section{Statistical Analysis}

Data were analyzed using Graph Pad prism 5.01 and expressed as mean \pm Standard Deviation (SD). The continuous variables were tested with one-way Analysis Of Variance (ANOVA) and Dunnet test. Values lower than 0.05 were considered statistically significant. 


\section{Results}

\section{Characterization of Clinical Isolates}

All the isolates were confirmed to be $S$. aureus as all these appeared as yellow colonies with yellow zones on the mannitol salt agar media after $24 \mathrm{~h}$ of incubation at $37^{\circ} \mathrm{C}$. Gram staining, catalase, oxidase and coagulase tests also confirmed that all the collected strains were $S$. aureus. Further screening of these isolates with methicillin disk confirmed approximately $48.1 \%(13 / 27)$ were MRSA. All the MRSA isolates produced a zone of inhibition $<10 \mathrm{~mm}$.

\section{Identification of NorA and NorB Genes in MRSA Strains}

Out of 13 MRSA strains, 8 strains were found to be positive for both NorA and NorB and 2 strains were positive only for NorA gene. All the strains positive for NorA and NorB genes were used for MIC and gene expression study.

\section{MIC}

As shown in Table 1, vancoplus appeared to be the most active antibacterial against NorA and NorB efflux pumps positive MRSA with MIC values of 0.25 to 0.5 $\mu \mathrm{g} \mathrm{mL} L^{-1}$. The second most active antibacterial agent was teicoplanin with MIC values of 0.5 to $1 \mu \mathrm{g} \mathrm{mL}$. The MIC of vancomycin and daptomycin ranged from 32 to $64 \mu \mathrm{g} \mathrm{mL}{ }^{-1}$. The MIC of linezolid ranged from 4 to $8 \mu \mathrm{g}$ $\mathrm{mL}^{-1}$. For gene expression study half of MIC of drugs was used.

\section{Effects of Drugs on NorA and NorB Gene Expression}

Our results revealed that the expression of NorA and NorB in the vancoplus treated group was down regulated approximately 9.3 and 9.9 fold, respectively as compared to the control $(\mathrm{P}<0.001)$, whereas other drugs such as vancomycin, linezolid, teicoplanin and daptomycin produced $0.12,0.36,0.65$ and 2.1 fold down regulation $(\mathrm{P}>0.05)$ of NorA gene, respectively and $0.16,0.32,0.74$ and 2.4 fold down regulation $(\mathrm{P}>0.05)$ of nor $B$ gene (Fig. 1A and B).

Table 1. Susceptibility study of drugs in NorA-NorB positive and NorA-NorB negative strains

\begin{tabular}{llr}
\hline & MIC $(\mu \mathrm{g} / \mathrm{mL})$ & \\
& - & \\
Drugs & NorA-NorB positive & NorA-NorB negative \\
\hline Teicoplanin & 0.5 to 1 & 0.13 \\
Linezolid & 4 to 8 & 0.25 \\
Daptomycin & 32 to 64 & 0.50 \\
Vancomycin & 32 to 64 & 1.00 \\
Vancoplus & 0.25 to 0.5 & 0.25 \\
\hline
\end{tabular}
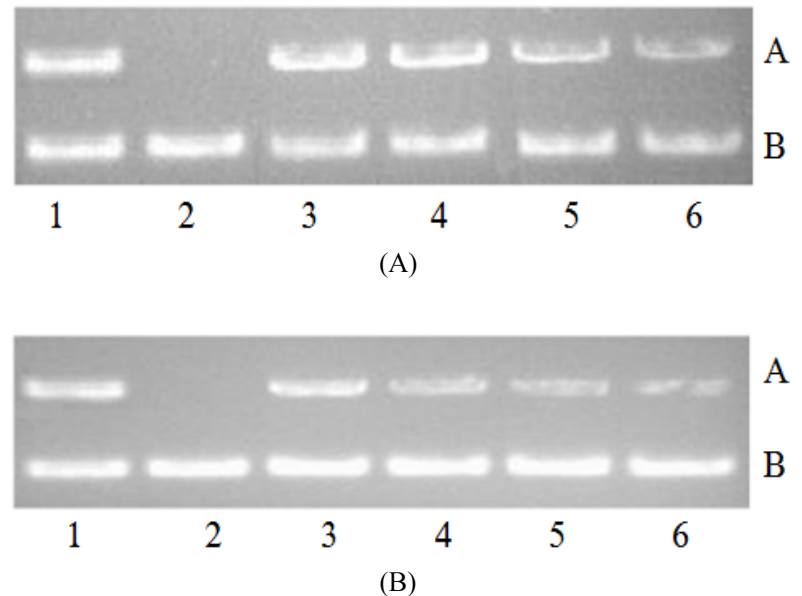

Fig.1. (A) Effect of drugs on NorA gene expression, in group A; $1=$ control (without treatment) $2=$ treated with Vancoplus; $3=$ treated with vancomycin; $4=$ treated with linezolid; $5=$ treated with teicoplanin; $6=$ treated with daptomycin. In group B; 1 to $6,16 \mathrm{~S}$ rDNA used as internal control (B) Effect of drugs on NorB gene expression, In group $A ; 1=$ control (without treatment) $2=$ treated with Vancoplus; $3=$ treated with vancomycin; $4=$ treated with linezolid; $5=$ treated with teicoplanin; $6=$ treated with daptomycin. In group B; 1 to $6,16 \mathrm{~S}$ rDNA used as internal control

\section{Discussion}

Efflux pumps are largely conserved in bacteria for self-defence and can be a potential target for effective antimicrobial therapy to treat infectious disease caused by multi drug resistant bacteria possessing efflux pumps. A number of methods have been used to identify the efflux systems in bacteria including use of radio labelled substrates, fluorometric assays or the determination of the MIC in the presence of efflux inhibitors (DeMarco et al., 2007; Patel et al., 2010; Kaatz et al., 2000). In our work from 13 clinical isolates only 8 isolates $(61.5 \%)$ were found to be NorA and NorB efflux pumps positive. A previous work reported $49 \%$ prevalence of NorB type efflux pump among $S$. aureus clinical isolates recovered from blood (DeMarco et al., 2007). Another study also demonstrated occurrence of NorB, MdeA or MepA type efflux pumps in S. aureus (Costa et al., 2011).

It has been reported that efflux pumps contribute a varying degree of resistance to antibacterial agents (Costa et al., 2013). The efflux activity has been correlated with increased resistance to antibiotics. It has been established that efflux pump inhibition might be associated with disturbance of the regulatory pathway required for efflux pump expression, modification of the chemical structure of the antibiotic inhibiting its attachment to specific substrates, hindrance of assembly of efflux pump components, inhibition of antibiotic by completive or non-completive binding, 
closing of the pores responsible for efflux of antimicrobial agents or disturbance of energy essential for pump activity (Poole and Lomovskaya, 2006; Pagés and Amaral, 2009). Our susceptibility data revealed that efflux pump positive isolates showed higher MIC compared to efflux pump deficient strains. Further, our data demonstrated that vancomycin+ceftriaxone+VRP1020 combination displayed a 4 fold reduction in MIC which might be due to synergistic activity of vancomycin+ceftriaxone+VRP1020. It has been suggested that efflux pumps belonging to the MFS, particularly NorA and NorB, utilize the proton motive force to energize the transport of antimicrobial compounds across the cell membrane, via an $\mathrm{H}+$ : Drug antiport mechanism (Costa et al., 2013; Martins et al., 2009).

It is thought that the effectiveness of an efflux pump inhibitor may be different when used with different antibiotics (Chevalier et al., 2010) and this may also depend on the level of expression of efflux pumps as well as the relative affinity of the antibiotic binding site for different antibiotics. Recently, the antimicrobial activity of tetracycline was enhanced by the addition of silver to bacterial cells that had been previously resistant to this antimicrobial agent (Morones-Ramirez et al., 2013).

Our study, when drugs at half MIC were studied on NorA and NorB gene expression coding NorA and NorB efflux pumps, revealed that vancoplus significantly $(\mathrm{P}<0.001)$ down regulated expression of both of these genes suggesting increased antibiotic accumulation within the bacteria.

\section{Conclusion}

Based on the observations, it is concluded that Vancoplus (vancomycin+ceftriaxone+VRP1020) can be one of the best choices to treat infections caused by MRSA possessing NorA and NorB efflux pumps.

\section{Acknowledgment}

Authors are thankful to the Emerging Antimicrobial Resistance Society, Chandigadh, India for providing assistance to carry out this study. We are also thankful to the Sanjay Gandhi Post Graduate Institute of Medical Sciences (SGPGIMS), Raebareli Road, Lucknow, India for providing clinical strains.

\section{Author's Contributions}

All authors equally contributed in this work.

\section{Ethics}

This article is original and contains unpublished material. The corresponding author confirms that all of the other authors have read and approved the manuscript and no ethical issues involved.

\section{References}

Akbar, A., A.K. Anal and F.A. Ansari, 2013. Prevalence and antibiogram study of Salmonella and Staphylococcus aureus in poultry meat. Asian Pac. J. Trop. Biomed., 3: 163-168.

DOI: $10.1016 / \mathrm{S} 2221-1691(13) 60043-\mathrm{X}$

Borges-Walmsley, M.I., K.S. McKeegan and A.R. Walmsley, 2003. Structure and function of efflux pumps that confer resistance to drugs. Biochem. J., 376: 313-338.

DOI: $10.1042 / B J 20020957$

Chaudhary, M., S. Kumar and A. Payasi, 2012. A novel approach to combat acquired multiple resistance in Escherichia coli by using EDTA as efflux pump inhibitor. J. Microb. Biochem. Technol., 4: 126-130. DOI: $10.4172 / 1948-5948.1000082$

CLSI, 2013. Methods for dilution antimicrobial susceptibility tests for bacteria that grow aerobically, approved standard-English edition. CLSI document M100-S23. CLSI, Wayne, PA 19087, USA.

Chevalier, J., A. Mahamoud, M. Baitiche, E. Adam and M. Viveiros et al., 2010. Quinazoline derivatives are efficient chemosensitizers of antibiotic activity in Enterobacter aerogenes, Klebsiella pneumoniae and Pseudomonas aeruginosa resistant strains. Int. J. Antimicrobial Agents, 36:164-8.

DOI: 10.1016/j.ijantimicag.2010.03.027

Costa, S.S., C. Falcão, M. Viveiros, D. Machado and M. Martins et al., 2011. Exploring the contribution of efflux on the resistance to fluoroquinolones in clinical isolates of Staphylococcus aureus. BMC Microbiol. DOI: 10.1186/1471-2180-11-241

Costa, S.S., M. Viveiros, L. Amaral and I. Couto, 2013. Multidrug efflux pumps in Staphylococcus aureus: An update. Open Microbiol. J., 7: 59-71. DOI: $10.2174 / 1874285801307010059$

DeMarco, C.E., L.A. Cushing, E. Frempong-Manso, S.M. Seo and T.A.A. Jaravaza et al., 2007. Efflux-related resistance to norfloxacin, dyes and biocides in bloodstream isolates of Staphylococcus aureus. Antimicrobial Agents Chem., 51: 3235-3239. DOI: 10.1128/AAC.00430-07

Ding, Y., Y. Onodera, J.C. Le and David C.H., NorB, 2008. NorB, an efflux pump in Staphylococcus aureus strain MW2, contributes to bacterial fitness in abscesses. J. Bacteriol., 190: 7123-9. DOI: $10.1128 /$ JB.00655-08

Handzlik, J., A. Matys and K. Kieć-Kononowicz, 2013. Recent advances in Multi-Drug Resistance (MDR) efflux pump inhibitors of gram-positive bacteria $S$. aureus. Antibiotics., 2: 28-45. DOI: $10.3390 /$ antibiotics2010028 
Jarmula, A., E. Oblak, D. Wawrzycka and J. Gutowicz, 2011. Efflux-mediated antimicrobial multidrug resistance. Postepy Hig. Med. Dosw., 65: 216227. DOI: $10.5604 / 17322693.937011$

Jadwiga S., K. Olech, A. Świst, D. Zając and J. Cabaj, 2013. Recent advances of modern protocol for C$\mathrm{C}$ bonds-the suzuki cross-coupling. Adv. Chem. Eng. Sci. DOI: 10.4236/aces.2013.33A1003

Kallen, A.J., Y. Mu, S. Bulens, A. Reingold and S. Petit et al., 2010. Active Bacterial Core surveillance (ABCs) MRSA investigators of the emerging infection program. Health care-associated invasive MRSA infections, J. Am. Med. Associat., 304: 641-8. DOI: $10.1001 /$ jama.2010.1115

Kaatz, G.W., S.M. Seo, L. O'Brien, M. Wahiduzzaman and T.J. Foster, 2000. Evidence for the existence of a multidrug efflux transporter distinct from NorA in Staphylococcus aureus. Antimicrobial Agents Chem., 44: 1404-1406.

DOI: 10.1128/AAC.44.5.1404-1406.2000

Kaatz, G.W., F. McAleese and S.M. Seo, 2005. Multidrug resistance in Staphylococcus aureus due to overexpression of a novel Multidrug And Toxin Extrusion (MATE) transport protein. Antimicrobial Agents Chem., 49: 1857-1864. DOI: 10.1128/AAC.49.5.1857-1864.2005

Li, X.Z. and H. Nikaido, 2009. Efflux-mediated drug resistance in bacteria: An update. Drugs, 69: 1555-1623. DOI: $10.2165 / 11317030-000000000-00000$

Markham, P.N. and A.A. Neyfakh, 2001. Effluxmediated drug resistance in Gram-positive bacteria. Current Opinion Microbiol., 4: 509-514. DOI: 10.1016/S1369-5274(00)00243-5

Martins, A., G. Spengler, L. Rodrigues, M. Viveiros and J. Ramos et al., 2009. pH modulation of efflux pump activity of multi-drug resistant Escherichia coli: Protection during its passage and eventual colonization of the colon. PLoS One. DOI: 10.1371/journal.pone.0006656

Morones-Ramirez, J.R., J.A. Winkler, C.S. Spina and J.J. Collins, 2013. Silver enhances antibiotic activity against gram-negative bacteria. Sci. Trans. Med., 5: 190: 181-190. DOI: 10.1126/scitranslmed.3006276

Neyfakh, A.A., C.M. Borsch and G.W. Kaatz, 1993. Fluoroquinolone resistance protein NorA of Staphylococcus aureus is a multidrug efflux transporter. Antimicrobial Agents Chem., 37: 128-9. DOI: 10.1128/AAC.37.1.128

Nikaido, H., 2003. Molecular basis of bacterial outer membrane permeability revisited. Microbiol. Mol. Biol. Rev., 67: 593-656.

DOI: 10.1128/MMBR.67.4.593-656.2003
Patel, N., M.H. Scheetz, G.L. Drusano and T.P. Lodise, 2010. Identification of optimal renal dosage adjustments for traditional and extended-infusion piperacillin-tazobactam dosing regimens in hospitalized patients. Antimicrobial Agents Chem., 54: 460-465. DOI: 10.1128/AAC.00296-09

Pagés, J.M. and L. Amaral, 2009. Mechanisms of drug efflux and strategies to combat them: Challenging the efflux pump of gram-negative bacteria. Biochim. Biophys. Acta, 1794: 826-833. DOI: $10.1016 /$ j.bbapap.2008.12.011

Poole, K., 2005. Efflux-mediated antimicrobial resistance. J. Antimicrobial Chem., 56: 20-51. DOI: $10.1093 /$ jac/dki171

Poole, K., O. Lomovskaya, 2006. Can efflux inhibitors really counter resistance $\mu$. Infect. Dis., 3: 145-152.

Ruiz, J., 2003. Mechanisms of resistance to quinolones: Target alterations, decreased accumulation and DNA gyrase protection. J. Antimicrobial Chem., 51: 11091117. DOI: $10.1093 / \mathrm{jac} / \mathrm{dkg} 222$

Sabatini, S., F. Gosetto, S. Serritella, G. Manfroni and O. Tabarrini et al., 2012. Pyrazolo[4,3c][1,2]benzothiazines 5,5-dioxide: A promising new class of Staphylococcus aureus NorA efflux pump inhibitors. J. Med. Chem., 55: 3568-3572. DOI: $10.1021 / \mathrm{jm} 201446 \mathrm{~h}$

Saiful, A.J., M. Mastura, S. Zarizal, M.I. Mazurah and M. Shuhaimi et al., 2008. Efflux genes and active efflux activity detection in Malaysian clinical isolates of Methicillin-Resistant Staphylococcus aureus (MRSA). J. Basic Microbiol., 48: 245-251. DOI: 10.1002/jobm.200700387

Sung, K., S.A. Khan, M.S. Nawaz and A.A. Khan, 2003. A simple and efficient Triton X-100 boiling and chloroform extraction method of RNA isolation from gram-positive and gram-negative bacteria. FEMS Microbiol. Lett., 229: 97-101. DOI: 10.1016/S0378-1097(03)00791-2

Truong-Bolduc, Q.C., P.M. Dunman, J. Strahilevitz, et al., 2005. MgrA is a multiple regulator of two new efflux pumps in Staphylococcus aureus. J. Bacteriol., 187: 2395-2405. DOI: 10.1128/JB.187.7.2395-2405.2005

Truong-Bolduc, Q.C., G.R. Bolduc, R. Okumura et al., 2011. Implication of the NorB efflux pump in the adaptation of Staphylococcus aureus to growth at acid $\mathrm{pH}$ and in resistance to moxifloxacin. Antimicrobial Agents Chem., 55: 3214-3219. DOI: 10.1128/AAC.00289-11

Truong-Bolduc, Q.C., L.C. Hsing, R. Villet et al., 2012. Reduced aeration affects the expression of the NorB efflux pump of Staphylococcus aureus by posttranslational modification of MgrA. J. Bacteriol., 194: 1823-34. DOI: 10.1128/JB.06503-11 